\title{
Effects of Acute-Partial Sleep Deprivation on High-Intensity Exercise Performance and Cardiac Autonomic Activity in Healthy Adolescents
}

\author{
Yue Zhang, Andi Liang, Jing Song, Yan Zhang, Xiaodan Niu, Tao Xiao and Aiping Chi *D \\ School of Sports, Shaanxi Normal University, Xi'an 710119, China; yuezhang@snnu.edu.cn (Y.Z.); \\ godfreyandy@snnu.edu.cn (A.L.); BSUjingjing@163.com (J.S.); yansalt12@snnu.edu.cn (Y.Z.); \\ nxd123456_@snnu.edu.cn (X.N.); xiaotty@snnu.edu.cn (T.X.) \\ * Correspondence: chimu@snnu.edu.cn; Tel.: +86-13008408400
}

Citation: Zhang, Y.; Liang, A.; Song, J.; Zhang, Y.; Niu, X.; Xiao, T.; Chi, A. Effects of Acute-Partial Sleep Deprivation on High-Intensity Exercise Performance and Cardiac Autonomic Activity in Healthy Adolescents. Sustainability 2021, 13, 8769. https://doi.org/10.3390/ su13168769

Academic Editors: Santos Villafaina, Juan Pedro Fuentes García and Daniel Collado-Mateo

Received: 30 June 2021

Accepted: 3 August 2021

Published: 5 August 2021

Publisher's Note: MDPI stays neutral with regard to jurisdictional claims in published maps and institutional affiliations.

Copyright: (c) 2021 by the authors. Licensee MDPI, Basel, Switzerland. This article is an open access article distributed under the terms and conditions of the Creative Commons Attribution (CC BY) license (https:// creativecommons.org/licenses/by/ $4.0 /)$.
Abstract: Performing high-intensity exercise (HIE) in the morning under sleep deprivation may harm the health benefits related to sufficient sleep and HIE. Therefore, the aim of this study was to explore the effects of acute-partial sleep deprivation on HIE performance and cardiac autonomic activity by monitoring heart rate variability (HRV) indices. Twenty-nine healthy male adolescents in college were recruited to perform a one-time HIE session on the treadmill (Bruce protocol) after $\geq 7 \mathrm{~h}$ of normal control sleep (control) and after $\leq 4 \mathrm{~h}$ of acute-partial sleep deprivation (SD). At the beginning of control and SD periods and after exercising under the two sleep conditions, heart rate (HR), standard deviation of normal to normal (SDNN), square root of the mean squared differences of successive NN intervals (RMSSD), normalized low frequency power (LFn), normalized high frequency power (HFn), number of pairs adjacent $\mathrm{NN}$ intervals differing by $\geq 50 \mathrm{~ms}$ in the entire recording count divided by the total number of all NN intervals (pNN50), and short axis and long axis value in Poincaré plot (SD1 and SD2) were measured at rest in an upright sitting position. The participants slept $7.63 \pm 0.52$ and $3.78 \pm 0.69 \mathrm{~h}$ during control and SD periods, respectively $(p<0.001)$. Compared with the control participants, those suffering sleep deprivation experienced a significant decrease in exercise duration, RMSSD, HFn, SD1, and pNN50 as well as a significant increase in maximum heart rate during exercise $(p<0.05)$. SDNN, RMSSD, HFn, SD1, and pNN50 decreased significantly after exercise ( $p<0.05$ and 0.01 and 0.001 , respectively). In summary, acute-partial sleep deprivation affected aerobic exercise performance the next morning and led to decreased cardiac vagus activity and cardiac autonomic dysfunction.

Keywords: vagus; athletic capacity; cardiac autonomic activity; fatigue after exercise

\section{Introduction}

In the past 20 years, the popularization of computers, networks, mobile phones, and electronic games has exerted a serious impact on adolescent lifestyle; delaying bed time has become a common habit among Chinese college and middle school students [1]. The American Sleep Foundation recommends that young individuals sleep for $\geq 7 \mathrm{~h}$ each night. While asleep time of $\leq 6 \mathrm{~h}$ is considered as mild sleep deprivation, that of $\leq 4 \mathrm{~h}$ is considered as severe sleep deprivation [2]. A lack of sleep may lead to a decline in many functions of physiological systems of the human body, including the nervous system [3], immune system [4], endocrine system [5], and cardiovascular system [6]. More importantly, much evidence has shown that lack of sleep may harm the cardiovascular system and neurocognitive functions $[7,8]$. Based on recent epidemiological studies, short-term sleep deprivation is associated with an increased risk of hypertension [9]. For Chinese students, studying is the main task of their life, so this sleep loss is of concern for adolescents because of presumed detriments to their study and life. 
The autonomic nervous system regulates physical variations during wakefulness and sleep in response to bodily stress, anxiety, or environmental changes by keeping the balance between sympathetic nervous system and parasympathetic nervous system activity $[10,11]$. It is known that lack of sleep affects cardiac autonomic function, but there is discrepancy in cardiac autonomic activity variation after sleep deprivation. Some studies have reported that sleep loss decreases cardiac vagus activity [12]. Consistent with this, total sleep deprivation caused an increase in heart rate (HR) and cardiac sympathetic activity in some research [13]. However, some studies have shown that there is no difference in HR and heart rate variability (HRV) following sleep deprivation [14]. Therefore, it seems that we will obtain different results depending on sleep deprivation protocols.

Increasing evidence upholds high-intensity exercise (HIE) for accomplishing various health benefits, as well as preventing cardiovascular disease and improving muscle strength $[15,16]$. The World Health Organization (WHO) recommends 75 to 150 min of HIE per week for healthy young people [17]. The popularity of HIE is mainly based on the fact that compared to low and moderate intensities, it can be performed in 10 to 30 min per session to achieve a great workout [18]. Since lack of time is the most common excuse for people not exercising [19], high-intensity exercise may be a time-efficient way to promote health and good body composition [20]. Some adolescents have to choose to exercise in the morning before their busy school and social life under sleep deprivation. Those people who may choose to exercise early in the morning after an overnight fast are more likely to improve fuel efficiency and utilization during exercise, and stimulate the accumulated fat burning effect in the body with increased fat usage [21-23]. Some reports have shown that exercise after an overnight fast in healthy men heightens alteration to training-induced muscle metabolic function [24]. Moreover, when $\mathrm{VO}_{2}$ max exceeds $65 \%$, fat oxidation in healthy men will increase during exercise after overnight fasting [25].

However, there is no doubt that performing HIE the following morning under an acutepartial sleep deprivation state significantly affects exercise performance due to a decrease in aerobic or anaerobic capacity, muscle strength, and impairment in related metabolic pathways [26]. The influence of acute-partial sleep loss prior to exercise performance programs has been partially investigated and there has been some discrepancy in anaerobic performance. Compared with the next morning's exercise performance, some researchers have pointed out a more obvious negative impact after partial sleep deprivation in the afternoon $[27,28]$. Consistent with this, different studies seem to confirm that acute sleep deprivation appears to have little effect on somatic function the next morning but can have a very significant negative effect in the afternoon $[27,29,30]$. In addition, other researchers have indicated that there is no difference in Wingate capability after $4 \mathrm{~h}$ of partial sleep deprivation $[27,31]$. However, in an experiment consisting in one night of sleep loss, partial sleep deprivation at the end of the night had a detrimental impact on anaerobic performance compared to the deprived situation at the start of the night [32]. A few researchers have concentrated on acute-partial sleep deprivation on aerobic performance, also producing controversial discoveries: one found evidence that sleep time was negatively correlated with the maximum heart rate (HRmax) in a maximal incremental cycle ergometer test [33]. Furthermore, another found Taekwondo athletes who slept $3 \mathrm{~h}$ had no change in their intermittent aerobic performance the next morning [34]. Likewise, another found no difference in the next day's exercise performance on a cycle ergometer between subjects with about $8 \mathrm{~h}$ of normal sleep and those with about $3 \mathrm{~h}$ of deprived sleep [30]. As shown in the aforementioned studies, the disagreement may be ascribed to differences in exercise intensities and protocols and the timing of exercise, nonuniformity of the analyzed variables, and to combinations of sleep deprivation projects in the form of time-lapse onset and periodic arousing [35].

HRV, which refers to a slight difference in interval between successive heartbeats (RR interval), is the result of the cardiac autonomic regulation of the sinus node and can reflect the function of the cardiac sympathetic and cardiac vagus nervous systems indirectly [36]. Generally, increased HRV indicates cardiac sympathetic withdrawal and 
cardiac vagus activation [37,38]. As a non-invasive marker, HRV monitoring is widely used for monitoring cardiac function, cardiovascular disease detection, and exercise load assessment $[14,15]$. HRV is lower at night during sleep compared to daytime, so researchers often use HRV indices to evaluate sleep quality $[39,40]$. It is well known that long-term and regular exercising can improve cardiac autonomic regulation ability [41]. Besides, HRV usually changes with an increase in exercise intensity, as the cardiac sympathetic system gradually dominates the cardiac vagus system, and the balance of the cardiac autonomic system changes significantly [42].

Acute-partial sleep deprivation among adolescents has become normal in Chinese society and has been less investigated than acute-total and chronic sleep deprivation. The influence of sleep and exercise may change cardiac autonomic activity, which may suggest some discrepancies based on the previous studies. Therefore, the main objective of the present study was to explore the effects of acute-partial sleep deprivation on HIE performance and cardiac autonomic activity in healthy adolescents. To this end, we performed a randomized and crossover study that compared $\geq 7 \mathrm{~h}$ of normal control sleep (control) with $\leq 4 \mathrm{~h}$ of acute-partial sleep deprivation (SD). We hypothesized that the HIE performance the next morning of healthy adolescents would be impaired after $\leq 4 \mathrm{~h}$ of acute partial-deprived sleep compared to $\geq 7 \mathrm{~h}$ of control sleep, and that the HRV before and after HIE would be decreased in the SD group compared to the control.

\section{Materials and Methods}

\subsection{Screening of Participants}

Thirty-four male college students aged 18 to 22 at Shaanxi Normal University participated in this study. All subjects were physically and mentally well as evaluated by questionnaires and had no history of cardiovascular diseases such as hypertension and sinus arrhythmia, assessed at the XueFu Hospital of Shaanxi Normal University by doctors. Subjects had healthy skeletal muscle and cardiopulmonary function with a $\mathrm{VO}_{2} \max \geq 50 \mathrm{~mL} / \mathrm{kg} / \mathrm{min}$ using the power cycle test. They reported no cigarette use for at least five years and regular work and rest arrangements. The Pittsburgh Sleep Quality Index (PSQI) is an accepted measure to investigate sleep quality and all subjects' habitual sleep quality was regarded as "good" as shown by the PSQI of $\leq 5$ and by wearing a sleep device to monitor habitual sleep duration for two weeks [43], which would ensure that they had no sleep barriers and had not deliberately stayed awake recently. Finally, we made sure that they were free of traces of drugs and alcohol abuse by urine testing. All subjects volunteered to participate in this study and signed an informed consent. The experimental protocol was approved by the research ethics committee of the Shaanxi Normal University institution.

\subsection{Preliminary Testing}

Body composition was estimated by body function monitor (Inbody, Shanghai, China) prior to performing predefined experimental protocols. After that, all participants were required to perform a $\mathrm{VO}_{2}$ max test in order to guarantee their aerobic capacity. After a short warm-up, participants began an incremental test on a cycle ergometer (Velotron; RacerMate Inc., Seattle, WA, USA) at 30 watts, increasing 30 watts every 2 min until voluntary completion. $\mathrm{VO}_{2}$ max was assessed continually with a gas analysis system (ParvoMedics, Sandy, UT, USA) during the entire test. We obtained results that the $\mathrm{VO}_{2}$ max of each participant was more than $50 \mathrm{~mL} / \mathrm{kg} / \mathrm{min}$.

\subsection{Experimental Conditions}

\subsubsection{Sleep Deprivation Protocol}

Subjects were prohibited coffee and alcohol use and physical activities at intensity of $60-75 \%$ of HRmax for one week prior to sleep testing [44]. Apart from that, they were instructed to maintain their habitual daily routine and diet and not to participate in this study if any physical or mental factors such as a cold, gastrointestinal discomfort, or anxiety arose during the study period. Importantly, we monitored the sleep efficiency and duration 
of subjects for one week before sleep deprivation protocols by the ActiGraph GT3-X+ (ActiGraph LLC, Pensacola, FL, USA) worn on their left wrist in order to confirm that they accorded with sleep conditions designated to them.

According to the American Sleep Foundation guidelines on the amount of night-time sleep needed in young individuals aged 18-25 [2], all subjects were separated into groups of either $\geq 7 \mathrm{~h}$ of control sleep or $\leq 4 \mathrm{~h}$ of SD and then were assigned the alternate sleep condition more than one week later. Subjects were required to set out to sleep between 22:30 and 23:30 $\mathrm{h}$ for the control group and then were awakened between 07:00 and 08:00 $\mathrm{h}$. For SD, they were instructed to sleep between 03:00 and 03:30 $\mathrm{h}$ and then were awakened as control [40] and stayed at a laboratory accompanied by an investigator until sleep preparations. During this period, activities such as chatting and enjoying electronic products were permitted for them. Upon eating their dinner, we asked them to take no extra food or drinks that interfere with sleep such as coffee and alcohol. In addition, subjects finished all sleep tasks at their dormitory in order to avert any possible insomnia and interruption from occurring during sleeping in a strange environment. Therefore, the study design permitted sufficient time for commuting and leisure time so that the corresponding sleep conditions could be met. Participants wore the ActiGraph GT3-X+ to monitor their respective sleep duration so investigators could check on whether they conformed to the sleep duration-related inclusion criteria for the control and SD conditions.

\subsubsection{High-Intensity Exercise Protocol}

The Bruce protocol [43] on the treadmill ( $\mathrm{h} / \mathrm{p} /$ cosmos, Munich, Germany) was used as the one-time high-intensity exercise protocol (Table 1), which was started at least $12 \mathrm{~h}$ after yesterday's dinner at about $08: 30 \mathrm{~h}$ the following morning. The participants wore watches (Garmin, Olathe, Kansas) to help us monitor and record ambulatory blood pressure and heart rate during the exercise. The Bruce protocol was started at a speed of $2.7 \mathrm{~km} / \mathrm{h}$ and a slope of $10 \%$ then increased by $1.3 \mathrm{~km} / \mathrm{h}$ and $2 \%$ every 3 min until exhaustion. Moreover, we adopted a questionnaire of the rating of perceived exertion (RPE) to record participants subjective feelings at the end of each level of exercise. We recorded the Bruce protocol level and total exercise time at the end of the exercise immediately.

Table 1. Exercise load at all levels of Bruce protocol.

\begin{tabular}{cccccccc}
\hline Parameters & Level 1 & Level 2 & Level 3 & Level 4 & Level 5 & Level 6 & Level 7 \\
\hline Speed $(\mathrm{km} / \mathrm{h})$ & 2.7 & 4.0 & 5.4 & 6.7 & 8.0 & 8.8 & 9.6 \\
Slope $(\%)$ & 10 & 12 & 14 & 16 & 18 & 20 & 22 \\
Duration (min) & 3 & 3 & 3 & 3 & 3 & 3 & 3 \\
\hline
\end{tabular}

Presence of any three of the following four conditions was a criterion for the termination of exhaustive exercise [45,46]. (1) Behavior: difficulty in breathing with profuse sweating; (2) blood pressure changes: systolic blood pressure of $\geq 150 \mathrm{~mm} \mathrm{Hg}$ and diastolic blood pressure of $\geq 75 \mathrm{~mm} \mathrm{Hg}$; (3) heart rate: a maximum heart rate of $\geq 180 \mathrm{bpm}$; (4) RPE level: reaching an RPE level of 18.

\subsection{HRV Collection and Analysis}

HRV was recorded by the ActiGraph GT3-X+ before and after HIE following the morning in an upright sitting position under a noise-free environment. HRV analysis included time domain, frequency domain, and nonlinear analysis. Time domain analysis was used to evaluate the activity of the cardiac sympathetic system and the vagus activity by recording RR interval during a set time and analyzing the standard deviation of successive heart beat (SDNN), root mean square of successive differences in RR intervals (RMSSD), and number of pairs of adjacent NN intervals differing by $\geq 50 \mathrm{~ms}$ in the entire recording count divided by the total number of all NN intervals (pNN50). In the frequency domain, the ECG signal of the tested individual was processed by fast Fourier transform to obtain high frequency power $(\mathrm{HF} ; 0.15-0.4 \mathrm{~Hz}$ ) and low frequency power $(\mathrm{LF} ; 0.04-0.15 \mathrm{~Hz})$. HF is basically a reflection of cardiac vagal activity, while both LF and LF/HF ratio provide total 
evaluation of sympathovagal balance [47]. LF and HF are presented in normalized units (LFn and HFn) and LF/HF were not embodied owing to algebraic redundancy [48]. The nonlinear analysis was based on dynamical and chaos cardiac theory; researchers usually choose a technique called Poincaré plot to reflect the overall irregular heartbeat and further reflect the function of the cardiac autonomic function [49].

We collected HRV for $5 \mathrm{~min}$ before and 5-10 min after HIE. After the completion of the test, the data on HR and RR intervals were output and RR intervals were input into the ActiLife software (version 6.11.4, ActiGraph LLC, Pensacola, FL, USA) for analysis. At the end, sleep duration, time domain indices including SDNN, RMSSD and pNN50, frequency domain indices including LFn and HFn, SD1 (short axis value in Poincaré plot), and SD2 (long axis value in Poincaré plot) associated with Poincaré plot were extracted. In addition, the power spectrum density (PSD) of each frequency band and Poincaré plot of distribution of RR intervals were also output, which would more intuitively reflect the change of HRV.

\subsection{Statistical Analysis}

All data were expressed as mean \pm standard deviation using a Kolmogorov-Smirnov test to ascertain the normality of the data. Blood pressure and HRmax during exercise and exercise duration were investigated using pairwise contrast to determine a significant difference. We compared SDNN, RMSSD, pNN50, HFn, LFn, SD1, and SD2 difference under the two sleep conditions and after HIE using a 2 (control sleep, sleep deprivation) $\times 2$ (before exercise, after exercise) analysis of variance (two-way ANOVA with repeated measures). When two-way rmANOVA showed a significant interaction $(p<0.05)$ or a main effect of one of the factors $(p<0.05)$, pairwise contrast was performed using the Bonferroni correction. The significance threshold was set at the 0.05 level.

Since this study had different dependent variables, a sample size of at least 15 participants was required [50], so a separate power analysis needed to be conducted to examine whether such a sample capacity was enough to test the hypothesis of this study. Furthermore, F-test, and ANOVA repeated measures were performed using Mac with G Power (version 3.1.94), within the interaction with the alpha level at 0.05 , power at 0.80 , one group, lower bound of sphericity at 1 , and effect size at 0.4 , for a total sample size of 12 . Therefore, a sample of 15 participants was reckoned appropriate to deduce statistical significance and conclude the results for the object of this research.

\section{Results}

\subsection{Pre-Experimental Data}

A total of 34 adolescents conformed to the inclusion criteria, but only 29 completed all preliminary protocols as required before the experiment. Three were excluded from this study because of violating regular sleep habits, and two for other reasons. The basic information of all proper subjects is presented in Table 2. Subjects were in good physical condition and able to complete HIE and sleep condition protocols.

Table 2. Basic information of subjects $(n=29)$.

\begin{tabular}{cc}
\hline Body Condition & Results \\
\hline Age (years) & $20.74 \pm 3.68$ \\
Gender & Male \\
Height $(\mathrm{cm})$ & $178.50 \pm 5.03$ \\
BMI $\left(\mathrm{kg} / \mathrm{m}^{2}\right)$ & $21.88 \pm 2.02$ \\
Weight $(\mathrm{kg})$ & $70.05 \pm 7.14$ \\
Basal metabolism/d (kcal) & $1759.00 \pm 160.02$ \\
Resting heart rate $(\mathrm{bpm})$ & $65.73 \pm 10.43$ \\
Resting SBP $(\mathrm{mmHg})$ & $119.60 \pm 14.74$ \\
Resting DBP $(\mathrm{mmHg})$ & $65.15 \pm 10.00$ \\
$\mathrm{VO}_{2}$ max $(\mathrm{mL} / \mathrm{kg} / \mathrm{min})$ & $52.79 \pm 18.49$ \\
\hline
\end{tabular}

Note: All data were presented as mean \pm standard deviation. BMI: body mass index; SBP: systolic blood pressure DBP: diastolic blood pressure. 


\subsection{Effects of Acute-Partial Sleep Deprivation on HIE Performance}

In this study, sleep duration of $\leq 4 \mathrm{~h}$ was used as the main condition to determine the successful establishment of the acute-partial sleep deprivation protocol. We found that the sleep duration of all subjects in the SD group was $\leq 4 \mathrm{~h}$ for $3.78 \pm 0.69 \mathrm{~h}$, while sleep in the control group was $\geq 7 \mathrm{~h}$ for $7.63 \pm 0.52 \mathrm{~h}$ (Table 3 ). There was significant difference between the two sleep conditions $(p<0.001)$, indicating that the sleep deprivation protocol in this study we designed was successfully established in line with the American Sleep Foundation's recommendation. In both SD and control groups, all subjects experienced dyspnea at the end of exercise. Their hearts rate reached $\geq 180 \mathrm{bpm}$ and RPE levels reached level 18; average systolic blood pressure and diastolic blood pressure at the end of exercise exceeded $150 \mathrm{~mm} \mathrm{Hg}$ and $75 \mathrm{~mm} \mathrm{Hg}$, respectively (shown in Table 3). The above results confirmed that the subjects met the conditions for exercise termination, thus fulfilling the purpose of HIE in this study. In addition, compared with the control group, the exercise duration of subjects with SD decreased significantly and the HRmax during exercise increased significantly $(p<0.05)$, indicating that acute-partial sleep deprivation could significantly harm subjects' HIE performance the following morning. Based on the results, sleep loss mainly influenced cardiovascular system function and thus caused poor HIE performance.

Table 3. Evaluation results for HIE protocol $(n=29)$.

\begin{tabular}{|c|c|c|c|c|c|c|c|}
\hline \multirow[b]{2}{*}{ Condition } & \multirow{2}{*}{$\begin{array}{l}\text { Sleep Duration } \\
\text { (h) }\end{array}$} & \multicolumn{5}{|c|}{ Condition of Exercise Termination } & \multirow{2}{*}{$\begin{array}{l}\text { Exercise Duration } \\
\text { (min) }\end{array}$} \\
\hline & & $\begin{array}{l}\text { Difficulty } \\
\text { Breathing }\end{array}$ & $\begin{array}{l}\text { SBP (Number of } \\
>150 \mathrm{mmHg})\end{array}$ & $\begin{array}{c}\text { DBP (Number of } \\
>75 \mathrm{mmHg})\end{array}$ & $\begin{array}{c}\mathrm{HR}_{\max } \text { (Number of } \\
>180 \mathrm{bpm})\end{array}$ & $R P E>18$ & \\
\hline Control & $7.63 \pm 0.52$ & all & $155.47 \pm 17.56(21)$ & $75.95 \pm 13.71(24)$ & $180.25 \pm 5.36$ (all) & all & $17.15 \pm 1.15$ \\
\hline SD & $3.78 \pm 0.69^{* * *}$ & all & $157.78 \pm 24.54(25)$ & $86.28 \pm 24.62(26)$ & $188.78 \pm 6.12$ (all) * & all & $16.55 \pm 1.07^{*}$ \\
\hline
\end{tabular}

Note: Values are mean \pm standard deviation. SBP: systolic blood pressure; DBP: diastolic blood pressure; HIE: high-intensity exercise; RPE: questionnaire of the rating of perceived exertion; control: $\geq 7 \mathrm{~h}$ of normal control sleep; SD: $\leq 4 \mathrm{~h}$ of acute-partial sleep deprivation; all: all participants match condition; vs. control, ${ }^{*}: p<0.05,{ }^{* * *}: p<0.001$.

\subsection{Results for HRV Indices}

\subsubsection{Two-Way rmANOVA for Main Effect}

All HRV indices were tested to obey normal distribution and we conducted a two-way rmANOVA for these indices. The main effect results for sleep condition are as follows: the main effect of SDNN was significant $\left(F_{(1,57)}=4.398, p=0.041, \eta^{2}=0.073\right)$; the main effect of RMSSD was significant $\left(F_{(1,57)}=9.065, p=0.004, \eta^{2}=0.139\right)$; the main effect of pNN50 was significant $\left(F_{(1,57)}=4.455, p=0.045, \eta^{2}=0.157\right)$; the main effect of HFn was significant $\left(F_{(1,57)}=9.127, p=0.004, \eta^{2}=0.140\right)$; the main effect of SD1 was significant $\left(F_{(1,57)}=5.081\right.$, $\left.p=0.028, \eta^{2}=0.083\right)$. There was no statistically significant main effect in LFn and SD2.

\subsubsection{Effects of Acute-Partial Sleep Deprivation on HRV}

The effects of acute-partial sleep deprivation on SDNN, RMSSD, pNN50 are shown in Table 4. Pairwise comparisons revealed that RMSSD and pNN50 were significantly lower in the SD group than in the control group $(p<0.05)$. However, there was no significant difference in SDNN between the two conditions. Compared with the control, acute-partial sleep deprivation resulted in a significant decrease in SD1 and HFn $(p<0.05)$, which is shown in Figures 1 and 2. The above results indicate that insufficient sleep duration mainly caused decreased cardiac vagus activity, but appeared to have little effect on cardiac sympathetic activity. 
Table 4. Comparison results of HRV time-domain indices before and after HIE ( $\mathrm{n}=29)$.

\begin{tabular}{ccccc}
\hline \multirow{2}{*}{ Index } & \multicolumn{2}{c}{ Pre- } & \multicolumn{2}{c}{ Post- } \\
\cline { 2 - 5 } & Control & SD & Control & SD \\
\hline SDNN (ms) & $39.82 \pm 12.40$ & $36.43 \pm 6.71$ & $13.42 \pm 7.29$ & $9.76 \pm 4.13^{*}$ \\
RMSSD (ms) & $47.28 \pm 11.93$ & $38.49 \pm 13.93^{*}$ & $9.86 \pm 5.34$ & $7.44 \pm 3.65^{* *}$ \\
pNN50 (\%) & $24.61 \pm 6.20$ & $21.78 \pm 5.85^{*}$ & $2.68 \pm 1.71$ & $0.25 \pm 0.23^{* * *}$ \\
\hline
\end{tabular}

Note: SDNN: the standard deviation of successive heart beat; RMSSD: root mean square of successive differences in RR intervals; pNN50: number of pairs adjacent NN intervals differing by $\geq 50 \mathrm{~ms}$ in the entire recording count divided by the total number of all NN intervals. SDNN, RMSSD and pNN50 were extracted for 5 min before and 5-10 min after HIE under control sleep and acute-partial sleep deprivation conditions. Values are mean \pm standard deviation vs. control, ${ }^{*}: p<0.05,{ }^{* *}: p<0.01,{ }^{* * *}: p<0.001$.

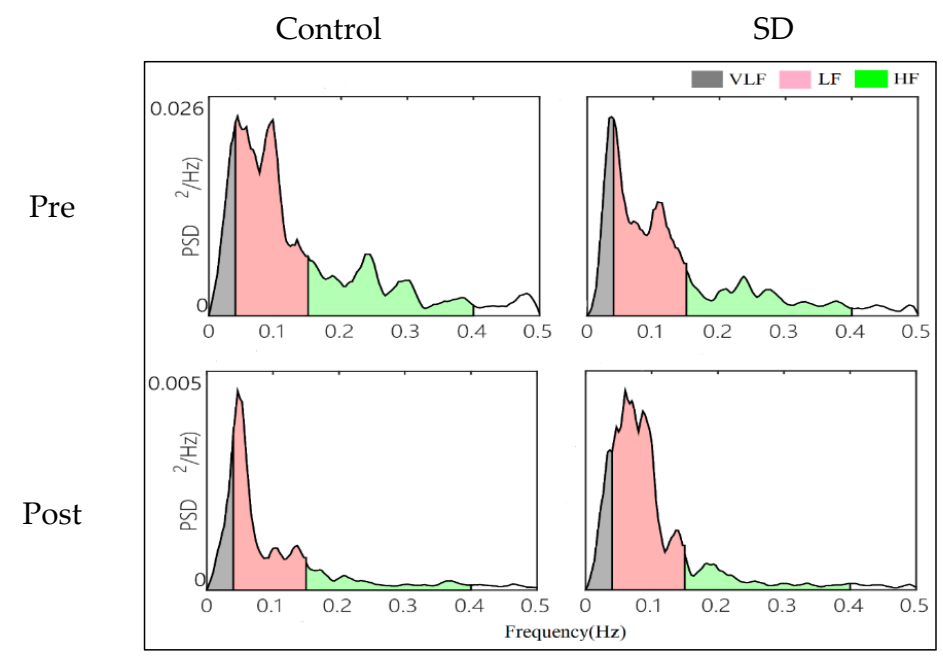

A
LFn
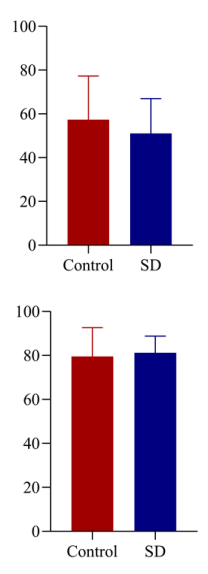

B
HFn
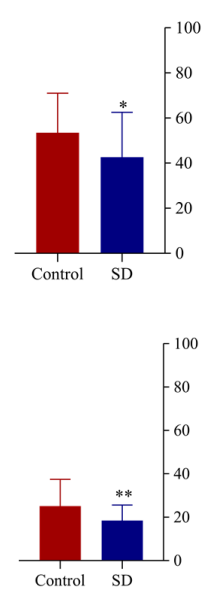

C

Figure 1. Detection result of frequency-domain indices before and after HIE. (A): Power spectrum density; VLF (0.0033 0.04 Hz), LF (0.04 0.15 Hz), HF (0.15 0.4 Hz); (B): low frequency normalized units (LFn) value; (C): high frequency normalized units (HFn) value; control: $\geq 7 \mathrm{~h}$ of normal control sleep; SD: $\leq 4 \mathrm{~h}$ of acute-partial sleep deprivation; vs. control, ${ }^{*}: p<0.05,{ }^{* *}: p<0.01$.

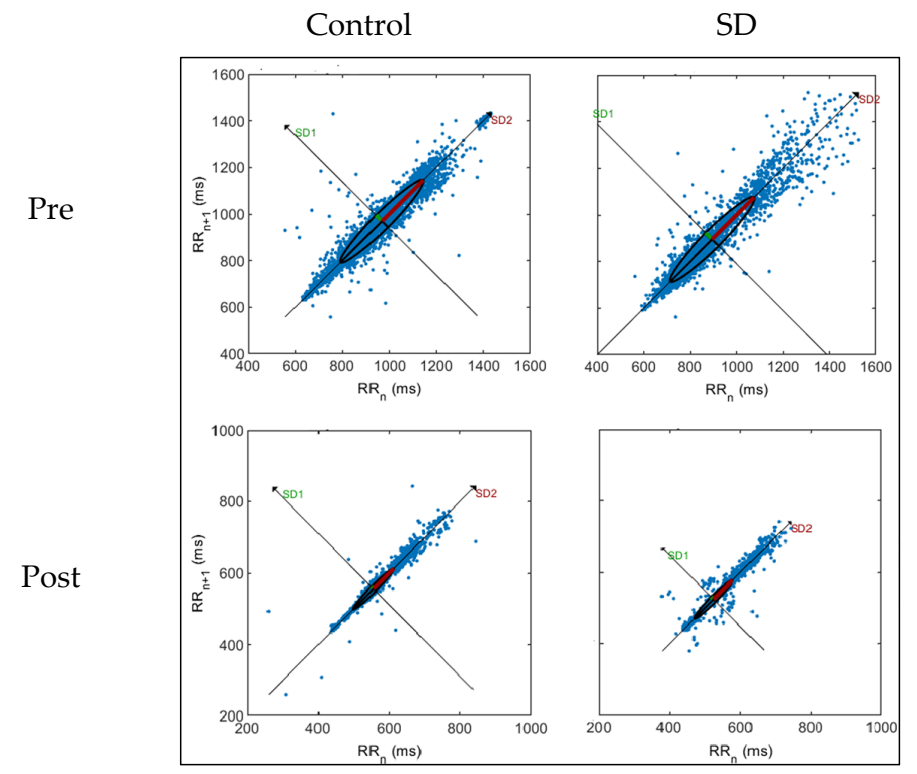

A
SD1
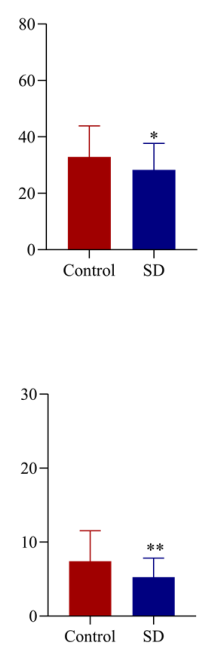

B
SD2
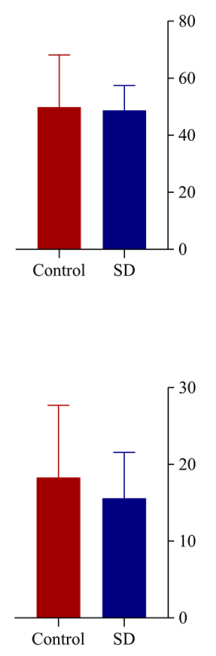

C

Figure 2. Detection result of nonlinear analysis before and after HIE. (A): Poincaré plot; (B): SD1 value (C): SD2 value; vs. control, ${ }^{*}: p<0.05,{ }^{* *}: p<0.01$. 


\subsubsection{Effects of Interaction of Acute-Partial Sleep Deprivation and HIE on HRV}

The effects of interaction of acute-partial sleep deprivation and HIE on SDNN, RMSSD, pNN50 are shown in Table 4. After sleep, subjects from both groups performed the HIE protocol the following morning. SDNN, RMSSD, and pNN50 were significantly lower in the SD group compared with the control ( $p<0.05$ and 0.01 and 0.001 , respectively). In addition, SD1, and HFn were significantly lower in the SD group compared with the control, which is shown in Figures 1 and $2(p<0.01)$. The above results indicate that effects of interaction of acute-partial sleep deprivation and HIE on HRV were more obvious than in an acute-partial sleep deprivation state only. Therefore, performing high intensity exercise in a sleep deprived condition would further harm the cardiac autonomic system owing to cardiac sympathetic activation during the exercise.

\section{Discussion}

This study established an acute-partial sleep deprivation model according to the recommendations of the American Sleep Foundation to determine the effects of short, insufficient sleep on high-intensity exercise performance and cardiac autonomic activity compared with a full night of rest. The basic finding was that next-morning HIE performance after acute-partial sleep deprivation was very likely impaired in terms of blood pressure and HRmax during the HIE, as well as final exercise duration. Futhermore, there was significant difference in HRmax and exercise duration. In addition, acute-partial sleep deprivation and in the case of HIE both result in varying degrees of HRV decrease. The above findings are consistent with our hypothesis. Anyhow, due to the restorative capabilities of sleep after a tired day, we have no difficulty in concluding that adequate sleep duration could promote good exercise performance the next morning.

However, it is hard to rate the results we have obtained against the background of the sleep and exercise performance because of disagreements on sample sizes, discrepancy in athletic ability, sleep deprivation protocols, the exercise time the next day that was completed, and finally the performance evaluation means [30,51]. The results of this study confirm the present vagueness of studies that analyze acute-partial sleep and aerobic performance by utilizing a high intensity exercise protocol [52].

Cycling performance was harmed the next morning $(08: 00 \mathrm{~h})$ when tested under acute sleep deprivation conditions ( $\leq 2.5 \mathrm{~h}$ ) compared with normal sleep conditions ( $\geq 7 \mathrm{~h})$ [37]; in the same study, there was a $4 \%$ decrease in $3 \mathrm{~km}$ cycling duration after restricting sleep. Cullen et al. also reported that 15 min exhaustion cycling duration was significantly lower the morning (07:00 to 09:00 h) following $4 \mathrm{~h}$ of sleep [53]. Likewise, in a more than 50 min cycling experiment, insufficient sleep duration $(\leq 4.5 \mathrm{~h})$ could still impair endurance performance the next morning compared with the control sleep group ( $\geq 7 \mathrm{~h})$ [54]. Our findings are consistent with the above results mainly due to a similar exercise protocol for high-intensity and long endurance exercise. Nevertheless, there are also some studies that have indicated that although acute-partial sleep deprivation has a detrimental effect on exercise performance the following morning, it does not suggest any difference in physical indices such as $\mathrm{VO}_{2}, \mathrm{VE}$, and RER and these variables may not change even after $64 \mathrm{~h}$ of sleep deprivation $[52,55]$. Other studies have suggested that morning exercise performance is unaffected by sleep conditions the previous night. There was no difference in the intermittent aerobic performance test scores for Taekwondo players the next morning after acute-partial sleep deprivation $(\leq 3 \mathrm{~h})$ compared with the control sleep group ( $\geq 7.5 \mathrm{~h}$ ) [56]. High-intensity interval exercise performance was not impaired by partial sleep deprivation (3-3.5 h) compared to those with enough sleep (9-9.5 h) [57]. In summary, influenced by the exercise protocols, it is possible that shorter exercise duration and lower intensity under controlled conditions was perceived as more easeful, arousing less fatigue and permitting subjects to perform the same protocol if in the SD group.

Regular robust sleep is accompanied by variations in the cardiac autonomic system. Some studies have shown that sleep deprivation could affect cardiac autonomic activity, leading in particular to a decrease in cardiac vagus activity as well as the dysfunction 
of cardiac autonomic function [12]. Meier-Ewert et al. [58] discovered that resting HR could increase after acute sleep deprivation for 10 nights, but after a night of acute sleep deprivation, blood pressure and HR were not influenced [59]. In addition, LFn was increased significantly after 12 and 24 but not $36 \mathrm{~h}$ of sleep deprivation [13]. Based on the previous studies, many studies have focused on the effects of acute-total sleep deprivation for at least 1 night on HR, blood pressure and HRV, but there is a lack of studies investigating acute-partial sleep deprivation affecting HRV. In this study, we monitored 5 min HRV before exercise to evaluate the change in cardiac autonomic activity under $\leq 4 \mathrm{~h}$ of acute-partial sleep deprivation conditions. RMSSD, pNN50, HFn, and SD1 were significantly lower compared to those with healthy sleep, which may indicate decreased cardiac vagus activity and a shift toward cardiac sympathetic modulation after acute-partial sleep deprivation.

The HRV change affected by exercise depends on its intensity and duration. Relevant studies have shown that there was no significant difference in HRV $10 \mathrm{~min}$ after lowintensity exercise compared to pre-exercise, which indicates that lower exercise load is not enough to stimulate the autonomic nervous system. However, HRV significantly decreased significantly after high-intensity exercise and does not return to baseline even $6 \mathrm{~h}$ after exercise [42], indicating that overload exercise may cause autonomic nervous system fatigue. The Bruce protocol used in this study involves a long-term HIE model, and the subjects under control and SD conditions eventually terminated the exercise session owing to exhaustion [60]. We collected 5 min HRV after HIE and SDNN, RMSSD, pNN50, HFn, and SD1 were lower compared to the control, and there was a more statistically significant difference after exercise than in participants under the two sleep conditions only, which indicated that HIE further impaired cardiac autonomic function based on the accumulated fatigue due to sleep deprivation. Therefore, it is possible that lower HRV after HIE observed in the current study were not a separate result of HIE, but rather a combination of fatigue caused by acute-partial sleep deprivation and fatigue that HIE caused.

Restrictions can be applied owing to the experiment protocol and investigated sample pattern, highlighting the demand for comprehensive studies implemented in the sleep deprivation survey domain with other groups such as females and individuals with normal athletic ability, as well as research that participates in similar or different exercise protocols and modes such as moderate intensity and interval exercise. In addition, with respect to the cardiac autonomic activity assessment means, only monitoring a 5 min HRV does not fully reflect cardiac autonomic activity: in order to perform it more comprehensively and accurately, $24 \mathrm{~h} \mathrm{HRV} \mathrm{collection} \mathrm{and} \mathrm{other} \mathrm{variables} \mathrm{such} \mathrm{as} \mathrm{blood} \mathrm{pressure} \mathrm{and} \mathrm{respiratory}$ rate could be involved in future research. Finally, to extend the future study based on the topic of sleep deprivation, the following covariates should be considered to reduce differences in results, such as health condition, sleep habits, and subjective feelings as to sleep quality [61,62]. In addition, more evidence from research with different perspectives is needed to confirm acute-partial sleep deprivation effects on single high-intensity exercise sessions.

\section{Conclusions}

Our findings suggest that acute-partial sleep deprivation $(\leq 4 \mathrm{~h})$ impairs high-intensity exercise performance the following morning and causes decreased cardiac vagus activity and cardiac autonomic dysfunction. The results of this study tell us that in order to maintain health, great aerobic capacity, and normal cardiac autonomic function, it is important to avoid sleep deprivation behavior and performing high-intensity exercise the next morning under sleep deprivation conditions.

Author Contributions: Data curation, X.N.; formal analysis, A.L. and Y.Z. (Yan Zhang); funding acquisition, A.C.; methodology, A.L.; resources, T.X.; software, J.S.; supervision, A.C.; visualization, Y.Z. (Yue Zhang); writing-original draft, Y.Z. (Yue Zhang). All authors have read and agreed to the published version of the manuscript. 
Funding: This research was supported by the National Natural Science Foundation of China (No. 31871209) and Shaanxi Normal University Graduate Student Innovation Team Project (Nos. TD2020003Z).

Institutional Review Board Statement: The study was conducted according to the guidelines of the Declaration of Helsinki, and approved by the Review Committee of Shaanxi Normal University (protocol code 202016005 and date of approval 17 January 2020).

Informed Consent Statement: Informed consent was obtained from all subjects involved in the study.

Data Availability Statement: Not applicable.

Acknowledgments: The authors want to thank the National Natural Science Foundation of China (No. 31871209) and Shaanxi Normal University Graduate Student Innovation Team Project (Nos. TD2020003Z).

Conflicts of Interest: The authors declare no conflict of interest.

\section{References}

1. Meng, Q.; Zhang, J.; Kang, J.; Wu, Y. Effects of sound environment on the sleep of college students in China. Sci. Total Environ. 2020, 705, 135794. [CrossRef]

2. Hirshkowitz, M.; Whiton, K.; Albert, S.M.; Alessi, C.; Bruni, O.; DonCarlos, L.; Hazen, N.; Herman, J.; Adams Hillard, P.J.; Katz, E.S.; et al. National Sleep Foundation's updated sleep duration recommendations: Final report. Sleep Health 2015, 1, 233-243. [CrossRef]

3. Toda, H.; Williams, J.A.; Gulledge, M.; Sehgal, A. A sleep-inducing gene, nemuri, links sleep and immune function in Drosophila. Science 2019, 363, 509-515. [CrossRef]

4. da Costa Souza, A.; Ribeiro, S. Sleep deprivation and gene expression. Curr. Top. Behav. Neurosci. 2015, 25, 65-90.

5. Morgan, D.; Tsai, S.C. Sleep and the Endocrine System. Sleep Med. Clin. 2016, 11, 115-126. [CrossRef]

6. Huang, T.; Mariani, S.; Redline, S. Sleep Irregularity and Risk of Cardiovascular Events: The Multi-Ethnic Study of Atherosclerosis. J. Am. Coll. Cardiol. 2020, 75, 991-999. [CrossRef]

7. Covassin, N.; Singh, P. Sleep Duration and Cardiovascular Disease Risk: Epidemiologic and Experimental Evidence. Sleep Med. Clin. 2016, 11, 81-89. [CrossRef] [PubMed]

8. Peiper, N.C.; Ridenour, T.A.; Fishbein, D.H. Characterizing psychiatric symptoms and neurocognitive functioning among substance-naïve early adolescents: Associations with sleep problems. Early Interv. Psychiatry 2020, 14, 439-449. [CrossRef]

9. Yang, H.; Baltzis, D.; Bhatt, V.; Haack, M.; Meier-Ewert, H.K.; Gautam, S.; Veves, A.; Mullington, J.M. Macro- and microvascular reactivity during repetitive exposure to shortened sleep: Sex differences. Sleep 2021, 44, zsaa257. [CrossRef]

10. Mellman, T.A.; Bell, K.A.; Abu-Bader, S.H.; Kobayashi, I. Neighborhood stress and autonomic nervous system activity during sleep. Sleep 2018, 41, 1-7. [CrossRef]

11. Yamanaka, Y.; Hashimoto, S.; Takasu, N.N.; Tanahashi, Y.; Nishide, S.Y.; Honma, S.; Honma, K. Morning and evening physical exercise differentially regulate the autonomic nervous system during nocturnal sleep in humans. Am. J. Physiol. Regul. Integr. Comp. Physiol. 2015, 309, R1112-R1121. [CrossRef]

12. Kiss, O.; Sydó, N.; Vargha, P.; Vágó, H.; Czimbalmos, C.; Édes, E.; Zima, E.; Apponyi, G.; Merkely, G.; Sydó, T.; et al. Detailed heart rate variability analysis in athletes. Clin. Auton. Res. 2016, 26, 245-252. [CrossRef] [PubMed]

13. Zhong, X.; Hilton, H.J.; Gates, G.J.; Jelic, S.; Stern, Y.; Bartels, M.N.; Demeersman, R.E.; Basner, R.C. Increased sympathetic and decreased parasympathetic cardiovascular modulation in normal humans with acute sleep deprivation. J. Appl. Physiol. 2005, 98, 2024-2032. [CrossRef] [PubMed]

14. Glos, M.; Fietze, I.; Blau, A.; Baumann, G.; Penzel, T. Cardiac autonomic modulation and sleepiness: Physiological consequences of sleep deprivation due to $40 \mathrm{~h}$ of prolonged wakefulness. Physiol. Behav. 2014, 125, 45-53. [CrossRef]

15. Boutcher, Y.N.; Boutcher, S.H. Exercise intensity and hypertension: What's new? J. Hum. Hypertens. 2017, 31, 157-164. [CrossRef]

16. Galloza, J.; Castillo, B.; Micheo, W. Benefits of Exercise in the Older Population. Phys. Med. Rehabil Clin. N. Am. 2017, 28, 659-669. [CrossRef] [PubMed]

17. González-Gross, M.; Meléndez, A. Sedentarism, active lifestyle and sport: Impact on health and obesity prevention. Nutr. Hosp. 2013, 28 (Suppl. 5), 89-98.

18. Heinrich, K.M.; Patel, P.M.; O'Neal, J.L.; Heinrich, B.S. High-intensity compared to moderate-intensity training for exercise initiation, enjoyment, adherence, and intentions: An intervention study. BMC Public Health 2014, 14, 789-795. [CrossRef]

19. Gibala, M.J.; Little, J.P.; Macdonald, M.J.; Hawley, J.A. Physiological adaptations to low-volume, high-intensity interval training in health and disease. J. Physiol 2012, 590, 1077-1084. [CrossRef]

20. Venn, D.; Strazdins, L. Your money or your time? How both types of scarcity matter to physical activity and healthy eating. Soc. Sci. Med. 2017, 172, 98-106. [CrossRef]

21. Zouhal, H.; Saeidi, A.; Salhi, A.; Li, H.; Essop, M.F.; Laher, I.; Rhibi, F.; Amani-Shalamzari, S.; Ben Abderrahman, A. Exercise Training and Fasting: Current Insights. Open Access J. Sports Med. 2020, 11, 1-28. [CrossRef] [PubMed] 
22. Wallis, G.A.; Gonzalez, J.T. Is exercise best served on an empty stomach? Proc. Nutr. Soc. 2019, 78, 110-117. [CrossRef]

23. Aird, T.P.; Davies, R.W.; Carson, B.P. Effects of fasted vs. fed-state exercise on performance and post-exercise metabolism: A systematic review and meta-analysis. Scand. J. Med. Sci. Sports 2018, 28, 1476-1493. [CrossRef] [PubMed]

24. Vieira, A.F.; Costa, R.R.; Macedo, R.C.; Coconcelli, L.; Kruel, L.F. Effects of aerobic exercise performed in fasted v. fed state on fat and carbohydrate metabolism in adults: A systematic review and meta-analysis. Br. J. Nutr. 2016, 116, 1153-1164. [CrossRef]

25. De Bock, K.; Richter, E.A.; Russell, A.P.; Eijnde, B.O.; Derave, W.; Ramaekers, M.; Koninckx, E.; Léger, B.; Verhaeghe, J.; Hespel, P. Exercise in the fasted state facilitates fibre type-specific intramyocellular lipid breakdown and stimulates glycogen resynthesis in humans. J. Physiol. 2005, 564 Pt 2, 649-660. [CrossRef]

26. Venables, M.C.; Jeukendrup, A.E. Endurance training and obesity: Effect on substrate metabolism and insulin sensitivity. Med. Sci. Sports Exerc. 2008, 40, 495-502. [CrossRef]

27. Abedelmalek, S.; Chtourou, H.; Aloui, A.; Aouichaoui, C.; Souissi, N.; Tabka, Z. Effect of time of day and partial sleep deprivation on plasma concentrations of IL-6 during a short-term maximal performance. Eur. J. Appl. Physiol. 2013, 113, 241-248. [CrossRef]

28. Roberson, P.A.; Chase, J.D.; Bigman, M.B.; Saunders, M.J.; Luden, N.D.; Womack, C.J. Time of day, but not sleep restriction, affects markers of hemostasis following heavy exercise. Appl. Physiol. Nutr. Metab. 2019, 44, 148-152. [CrossRef]

29. Fullagar, H.H.; Skorski, S.; Duffield, R.; Julian, R.; Bartlett, J.; Meyer, T. Impaired sleep and recovery after night matches in elite football players. J. Sports Sci. 2016, 34, 1333-1339. [CrossRef]

30. Mejri, M.A.; Yousfi, N.; Mhenni, T.; Tayech, A.; Hammouda, O.; Driss, T.; Chaouachi, A.; Souissi, N. Does one night of partial sleep deprivation affect the evening performance during intermittent exercise in Taekwondo players? J. Exerc. Rehabil. 2016, 12, 47-53. [CrossRef]

31. Souissi, N.; Souissi, M.; Souissi, H.; Chamari, K.; Tabka, Z.; Dogui, M.; Davenne, D. Effect of time of day and partial sleep deprivation on short-term, high-power output. Chronobiol. Int. 2008, 25, 1062-1076. [CrossRef]

32. Vitale, K.C.; Owens, R.; Hopkins, S.R.; Malhotra, A. Sleep Hygiene for Optimizing Recovery in Athletes: Review and Recommendations. Int. J. Sports Med. 2019, 40, 535-543. [CrossRef]

33. Antunes, B.M.; Campos, E.Z.; Parmezzani, S.S.; Santos, R.V.; Franchini, E.; Lira, F.S. Sleep quality and duration are associated with performance in maximal incremental test. Physiol. Behav. 2017, 177, 252-256. [CrossRef]

34. Grandner, M.A.; Hale, L.; Moore, M.; Patel, N.P. Mortality associated with short sleep duration: The evidence, the possible mechanisms, and the future. Sleep Med. Rev. 2010, 14, 191-203. [CrossRef]

35. Chase, J.D.; Roberson, P.A.; Saunders, M.J.; Hargens, T.A.; Womack, C.J.; Luden, N.D. One night of sleep restriction following heavy exercise impairs 3-km cycling time-trial performance in the morning. Appl. Physiol. Nutr. Metab. 2017, 42, 909-915. [CrossRef]

36. Khan, A.A.; Lip, G.Y.H.; Shantsila, A. Heart rate variability in atrial fibrillation: The balance between sympathetic and parasympathetic nervous system. Eur. J. Clin. Investig. 2019, 49, e13174. [CrossRef]

37. Kaltsatou, A.; Hadjigeorgiou, G.M.; Grigoriou, S.S.; Karatzaferi, C.; Giannaki, C.D.; Lavdas, E.; Fotiou, D.; Kouidi, E.; Patramani, G.; Vogiatzi, C.; et al. Cardiac autonomic function during intradialytic exercise training. Postgrad. Med. 2019, 131, 539-545. [CrossRef]

38. Tan, J.P.H.; Beilharz, J.E.; Vollmer-Conna, U.; Cvejic, E. Heart rate variability as a marker of healthy ageing. Int. J. Cardiol. 2019, 275, 101-103. [CrossRef]

39. Zhang, L.; Wu, H.; Zhang, X.; Wei, X.; Hou, F.; Ma, Y. Sleep heart rate variability assists the automatic prediction of long-term cardiovascular outcomes. Sleep Med. 2020, 67, 217-224. [CrossRef]

40. Lee, H.J.; Hwang, S.H.; Yoon, H.N.; Lee, W.K.; Park, K.S. Heart Rate Variability Monitoring during Sleep Based on Capacitively Coupled Textile Electrodes on a Bed. Sensors 2015, 15, 11295-11311. [CrossRef] [PubMed]

41. Wu, N.N.; Tian, H.; Chen, P.; Wang, D.; Ren, J.; Zhang, Y. Physical Exercise and Selective Autophagy: Benefit and Risk on Cardiovascular Health. Cells 2019, 8, 1436. [CrossRef]

42. Michael, S.; Jay, O.; Halaki, M.; Graham, K.; Davis, G.M. Submaximal exercise intensity modulates acute post-exercise heart rate variability. Eur. J. Appl. Physiol. 2016, 116, 697-706. [CrossRef] [PubMed]

43. Mollayeva, T.; Thurairajah, P.; Burton, K.; Mollayeva, S.; Shapiro, C.M.; Colantonio, A. The Pittsburgh sleep quality index as a screening tool for sleep dysfunction in clinical and non-clinical samples: A systematic review and meta-analysis. Sleep Med. Rev. 2016, 25, 52-73. [CrossRef] [PubMed]

44. Alansare, A.; Alford, K.; Lee, S.; Church, T.; Jung, H.C. The Effects of High-Intensity Interval Training vs. Moderate-Intensity Continuous Training on Heart Rate Variability in Physically Inactive Adults. Int. J. Environ. Res. Public Health 2018, 15, 1508, [CrossRef] [PubMed]

45. Itagi, A.B.H.; Patil, N.A.; Kotian, R.K.; Reddy, S.K.; Abhyankar, S.; Parveen, R.S. Physical Exhaustion Induced Variations in Event-Related Potentials and Cognitive Task Performance in Young Adults. Ann. Neurosci. 2018, 25, 299-304. [CrossRef] [PubMed]

46. Wu, C.H.; Karageorghis, C.I.; Wang, C.C.; Chu, C.H.; Kao, S.C.; Hung, T.M.; Chang, Y.K. Effects of acute aerobic and resistance exercise on executive function: An ERP study. J. Sci. Med. Sport 2019, 22, 1367-1372. [CrossRef]

47. Heathers, J.A. Everything Hertz: Methodological issues in short-term frequency-domain HRV. Front. Physiol. 2014, 5, 177-191. [CrossRef]

48. Burr, R.L. Interpretation of normalized spectral heart rate variability indices in sleep research: A critical review. Sleep 2007, 30, 913-919. [CrossRef] 
49. Brennan, M.; Palaniswami, M.; Kamen, P. Do existing measures of Poincaré plot geometry reflect nonlinear features of heart rate variability? IEEE Trans. Biomed. Eng. 2001, 48, 1342-1347. [CrossRef] [PubMed]

50. Zhang, J.Q.; Ji, L.L.; Fretwell, V.S.; Nunez, G. Effect of exercise on postprandial lipemia in men with hypertriglyceridemia. Eur. J. Appl. Physiol. 2006, 98, 575-582. [CrossRef] [PubMed]

51. Milz, P.; Faber, P.L.; Lehmann, D.; Koenig, T.; Kochi, K.; Pascual-Marqui, R.D. The functional significance of EEG microstatesAssociations with modalities of thinking. Neuroimage 2016, 125, 643-656. [CrossRef]

52. Azboy, O.; Kaygisiz, Z. Effects of sleep deprivation on cardiorespiratory functions of the runners and volleyball players during rest and exercise. Acta Physiol. Hung. 2009, 96, 29-36. [CrossRef]

53. Cullen, T.; Thomas, G.; Wadley, A.J.; Myers, T. The effects of a single night of complete and partial sleep deprivation on physical and cognitive performance: A Bayesian analysis. J. Sports Sci. 2019, 37, 2726-2734. [CrossRef]

54. Roberts, S.S.H.; Teo, W.P.; Aisbett, B.; Warmington, S.A. Extended Sleep Maintains Endurance Performance Better than Normal or Restricted Sleep. Med. Sci. Sports Exerc. 2019, 51, 2516-2523. [CrossRef]

55. Oliver, S.J.; Costa, R.J.; Laing, S.J.; Bilzon, J.L.; Walsh, N.P. One night of sleep deprivation decreases treadmill endurance performance. Eur. J. Appl. Physiol. 2009, 107, 155-161. [CrossRef]

56. Mejri, M.A.; Hammouda, O.; Zouaoui, K.; Chaouachi, A.; Chamari, K.; Rayana, M.C.B.; Souissi, N. Effect of two types of partial sleep deprivation on Taekwondo players' performance during intermittent exercise. Biol. Rhythm. Res. 2013, 45, 17-26. [CrossRef]

57. Papadakis, Z.; Forsse, J.S.; Stamatis, A. High-Intensity Interval Exercise Performance and Short-Term Metabolic Responses to Overnight-Fasted Acute-Partial Sleep Deprivation. Int. J. Environ. Res. Public Health 2021, 18, 3655. [CrossRef]

58. Meier-Ewert, H.K.; Ridker, P.M.; Rifai, N.; Regan, M.M.; Price, N.J.; Dinges, D.F.; Mullington, J.M. Effect of sleep loss on C-reactive protein, an inflammatory marker of cardiovascular risk. J. Am. Coll. Cardiol. 2004, 43, 678-683. [CrossRef]

59. Kato, M.; Phillips, B.G.; Sigurdsson, G.; Narkiewicz, K.; Pesek, C.A.; Somers, V.K. Effects of sleep deprivation on neural circulatory control. Hypertension 2000, 35, 1173-1175. [CrossRef]

60. Sarma, S.; Levine, B.D. Beyond the Bruce Protocol: Advanced Exercise Testing for the Sports Cardiologist. Cardiol. Clin. 2016, 34, 603-608. [CrossRef]

61. Tekieh, T.; Lockley, S.W.; Robinson, P.A.; McCloskey, S.; Zobaer, M.S.; Postnova, S. Modeling melanopsin-mediated effects of light on circadian phase, melatonin suppression, and subjective sleepiness. J. Pineal Res. 2020, 69, e12681. [CrossRef] [PubMed]

62. Zobaer, M.S. Physiology-Based Modeling of Sleep and Wake Phenomena in the Human Brain. Ph.D. Thesis, The University of Sydney, Sydney, Australia, 2018. 